\title{
The Lexical Constituency Model: Some Implications of Research on Chinese for General Theories of Reading
}

\author{
Charles A. Perfetti and Ying Liu \\ University of Pittsburgh
}

\author{
Li Hai Tan \\ Hong Kong University
}

\begin{abstract}
The authors examine the implications of research on Chinese for theories of reading and propose the lexical constituency model as a general framework for word reading across writing systems. Word identities are defined by 3 interlinked constituents (orthographic, phonological, and semantic). The implemented model simulates the time course of graphic, phonological, and semantic priming effects, including immediate graphic facilitation followed by graphic inhibition with simultaneous phonological facilitation, a pattern unique to the Chinese writing system. Pseudocharacter primes produced only facilitation, supporting the model's assumption that lexical thresholds determine phonological and semantic, but not graphic, effects. More generally, both universal reading processes and writing system constraints exist. Although phonology is universal, its activation process depends on how the writing system structures graphic units.
\end{abstract}

The development of models of word reading has been informed primarily by studies of English word identification. This is true for both symbolic models that postulate an internal lexicon and multiple pathways to pronunciation (Besner \& Smith, 1992; Coltheart, 1978; Coltheart, Curtis, Atkins, \& Haller, 1993; Paap \& Noel, 1991) and nonsymbolic models that assume a single mechanism without a lexicon (Harm \& Seidenberg, 1999; Seidenberg \& McClelland, 1989; Plaut, McClelland, Seidenberg, \& Patterson, 1996; Van Orden, Pennington, \& Stone, 1990). Furthermore, the testing grounds for these models have been empirical studies of English word reading. Models that may extend beyond English (Berent \& Perfetti, 1995; Grainger \& Jacobs, 1994, 1996; Jacobs, Rey, Ziegler, \& Grainger, 1998) remain essentially models of reading in alphabetic writing systems. Meanwhile, the comparative study of orthographies has focused on the reliability of orthographic mappings to phonology (e.g., Frost, Katz, \& Bentin, 1987), but its empirical focus has been on variations within the family of alphabetic systems, including the special cases of vowel-less spellings (Baluch \& Besner, 1991; Frost, 1994, 1995).

In recent years, however, research on reading in nonalphabetic writing systems has accumulated sufficiently to invite comparisons with alphabetic reading and to ask what kinds of models can explain reading in these systems. Both Japanese Kana, a syllabic system, and Chinese, traditionally considered a logographic sys-

Charles A. Perfetti and Ying Liu, Learning Research \& Development Center, University of Pittsburgh; Li Hai Tan, Department of Linguistics, Hong Kong University, Hong Kong, China.

This research was supported by National Science Foundation Grant 0113243. Li Hai Tan was supported by a Hong Kong Government Research Grants Council Central Allocation grant (HKU 3/02C). We thank Danling Peng for use of the cognitive research lab at Beijing Normal University, Beijing, China, and Susan Dunlap for assistance on the final version.

Correspondence concerning this article should be addressed to Charles A. Perfetti, Learning Research \& Development Center, University of Pittsburgh, Pittsburgh, PA 15260. E-mail: Perfetti@pitt.edu tem, have been the focus of research. Because the Chinese system, as used in China and derivatively elsewhere in East Asia (e.g., Japanese Kanji), presents the highest contrast to alphabetic systems, it provides an especially interesting comparison with alphabetic reading.

One point of comparison is a theory of word reading. English language research has been occupied with how to explain the facts of word pronunciation. How is it that readers can read both words that vary in the reliability of their grapheme-phoneme correspondences and nonwords? Skilled readers can read exceptional words, whose pronunciations cannot be predicted by mapping the letters to their usual ("regular") phoneme correspondences (e.g., colonel). They can also read letter strings that are not words at all (e.g., slape). To solve the problem posed by the breadth of these abilities, dual-route models (Coltheart et al., 1993; Coltheart, Rastle, Perry, Langdon, \& Ziegler, 2001) assume that there are two distinct procedures for pronouncing letter strings. One procedure, the lexical route, accesses a lexical representation and reads out its stored pronunciation. The second procedure, the sublexical route, assembles successive grapheme-phoneme mappings, producing the outcome of the assembly as a pronunciation. The lexical route must be used for correct pronunciation of exceptional words such as colonel and the sublexical route must be used for nonwords, which do not have lexical entries. Regular words can be read correctly by either procedure, with the procedure for any word reading event dependent on other factors, especially word frequency. Consistent with this assumption of the model, naming experiments produce a Frequency $\times$ Regularity interaction-regularity matters more for low-frequency than for high-frequency words.

The single route models compute pronunciations from a single type of sublexical input-output connection and thus have no lexical procedure (Seidenberg \& McClelland, 1989; Plaut et al., 1996). The single route models, by relying on learning that changes the connection weights between sublexical units, provide an account for the Frequency $\times$ Regularity interaction. However, their success in reading nonwords is a matter for dispute (Besner, 
1990; Coltheart et al., 1993; Seidenberg \& McClelland, 1990) and has helped motivate model revisions (Plaut et al., 1996; Harm \& Seidenberg, 1999).

In this context, we can ask what forms these questions take in nonalphabetic reading and whether they are solved by models that include lexical representations and lexical procedures. For Chinese, such questions have been addressed only by analogy with alphabetic systems. For example, does reading Chinese show an analogy to the Regularity $\times$ Frequency interaction, despite the fact that "regularity" does not apply to Chinese in the way it is defined in English (e.g., Seidenberg, 1985; Fang, Horng, \& Tzeng, 1986)? The analogy has led to general, tentative conclusions; for example, in all systems, there develops a pool of high-frequency words that can be read directly from graphic input without the intervention of assembled phonology (Seidenberg, 1985). However, there has not been a focus on Chinese reading at a theoretical level that would explain both its universal and distinctive properties in any detail. By now, there are sufficient data to begin to develop some interesting theoretical questions. At one level, these data can pose a challenge to models of reading: Are the models developed in alphabetic reading sufficient to explain nonalphabetic reading? What are the critical differences between Chinese reading and English reading? At a more concrete level, the question is what are the emerging empirical features of Chinese reading that need to be explained in a model of reading?

In the sections that follow, we focus first on the more concrete question, by describing a model of Chinese word reading and the research findings that motivate it. We then turn to the more general question that connects the issues that emerge in Chinese reading to general theories of word reading. First, however, we provide a general framework for comparative analysis and review the basic nature of the Chinese writing system and how it is read.

\section{The Comparative Analysis of Word Reading}

In comparative studies of reading, there are two points of comparison: The language and the writing system. Thus, in comparing Chinese and English reading, we compare examples of two unrelated language families. Chinese actually includes several languages and dialects (e.g., Mandarin, Cantonese [Yue], Min, Hunanese) that belong to the Sino-Tibetan language family. Compared with English, Chinese is more monosyllabic, it contains more open (consonant-vowel) syllables and it uses tones phonemically; that is, tones are necessary to distinguish morphemes that are otherwise phonemically identical. Such language factors are inevitably linked to reading, because reading is built on the language system.

Indeed, linguistic variables, quite independent of the writing system, can affect reading strategies. One example comes from comparisons of English with Hangul, the Korean alphabetic system. Hangul and English show differences in the subsyllabic units used by readers. English readers are sensitive to onset-rime structures (e.g., pin analyzed as $p+i n$ ), whereas Korean readers are sensitive to body-coda structures (e.g. pin analyzed as $p i+n$ ) (Yoon, Bolger, Kwon, \& Perfetti, 2002). Moreover, parallel differences are found when Korean and English speakers make judgments of spoken language, suggesting that the source of the syllable structure difference observed in reading is in the language rather than in the writing system. Thus, linguistic differences are a matter for comparisons of reading, and the detailed nature of their impact needs to be an important goal for comparative reading studies. However, to maintain our focus on writing system differences, we turn from language differences to an analysis of the Chinese writing system and Chinese word reading.

\section{The Chinese Writing System}

Historically, the Chinese writing system has been viewed as meaning-based rather than speech-based. Thus, it seemed reasonable to suppose that Chinese silent reading works as a visual form-to-meaning system. But research has forced a new understanding of Chinese reading. At the text and sentence level, written Chinese, like written English, involves phonological processes that support memory and comprehension (Tzeng, Hung, \& Wang, 1977; Zhang \& Perfetti, 1993). More surprisingly, as summarized in a review by Tan and Perfetti (1998), the evidence for phonology in Chinese reading extends down to the reading of single words in meaning tasks. The explanation for these discoveries seems to require highly general, probably universal, print-to-speech processes, even with constraints imposed by writing systems.

To appreciate the nonobviousness of this conclusion, one must understand the basis of the Chinese writing system. Although it is typical to refer to written Chinese as a logographic system, it seems more correct to describe it as morphemic (e.g., Leong, 1973) or even morphosyllabic (e.g., DeFrancis, 1989; Mattingly, 1992). A character, as a basic writing unit, maps onto a single syllable morpheme - not a phoneme - in the spoken language. A single morpheme usually can be considered a word in the spoken language, although multimorpheme (and, hence, multisyllable) words are common.

The morphemic nature of Chinese writing leads easily to the assumption of a close connection between graphic form and meaning. First, some researchers have concluded that simple Chinese characters (pictographs and their derivatives) are encoded as images that vividly signal meaning (I.-M. Liu, 1995; Wang, 1973). Second, in compound characters, one or more semantic components (semantic radicals) inside the character may suggest the character's meaning. The combined effect of these aspects of Chinese writing leads to an inference that meaning is obtained directly from the character form with no role for the spoken language form associated with the character.

Adding to this belief, perhaps, is a fact from the language side: the pervasive homophony of Chinese. Modern-day usage includes 420 distinct syllables (disregarding tone) mapped onto about 4,574 characters (Language and Teaching Institute of Beijing Linguistic College, 1986). Thus, on average, 11 characters share a single pronunciation. Tone disambiguates a large number of these cases, but ample ambiguity remains (about four homophones for each character). Thus, it would be functional for reading to be able to ignore pronunciation, because pronunciation itself is not very helpful in selecting meaning. In spoken Chinese, context plays a large role in selecting a spoken word from among its phonetically similar cohorts (Li \& Yip, 1996). In reading, the writing system allows characters with the same pronunciation to be disambiguated by their graphic forms. Thus, a graphic form serves, in principle, to select meaning and escape homophony. 
In summary, there have been at least three reasons-two concerning the writing system and one concerning the spoken language-for the tendency to characterize written Chinese as a script-to-meaning system: (a) the pictographic origins of the characters, (b) the presence of semantic radicals in character compounds, and (c) the extensive presence of homophones in the spoken language. However, there are counterpoints to each of these. First, the pictographic content of modern Chinese has long been negligible. DeFrancis (1989) has estimated pictographs at less than $1 \%$ of the character lexicon. Second, the facts about semantic information in compounds are a bit more complex, as explained below. The rebuttal to the third point is not brief, so we delay it until the General Discussion.

The composition of compounds is important because compounds of two or more components make up the majority of characters in Chinese. These components, known as radicals, can provide information about meaning (semantic radicals) and pronunciation (phonetic radicals). A small minority of compound characters has two semantic radicals; others have one semantic radical and one phonetic radical (phonetic compounds). About $85 \%$ of present-day characters are phonetic compounds (Perfetti \& Tan, 1998; Zhu, 1988).

To illustrate, 日 is a simple character pronounced /ri/4 (the number represents one of the four tones in Mandarin Chinese) and has the meaning sun. The compound character 青 (/qing/1, meaning green) is composed of one top and one bottom radical. These two characters combine with ri4 on the left and qing1 on the right to produce the character 晴, pronounced /qing/2, which has the meaning sunshine. Thus, this last compound is related in meaning to its left radical and in pronunciation to its right radical. (Notice that the pronunciation similarity in this case includes phonemes but not tone.) Thus, sunshine represents a compound whose component radicals have both semantic and phonetic validity.

Although most compounds have a degree of semantic validitythat is, some aspect of their meaning is suggested by a semantic component (Fan, 1986; Jin, 1985) — this depends on the frequency of the compound. Semantic validity increases with decreasing printed frequency of the compound character (Perfetti, Zhang, \& Berent, 1992). This same frequency effect holds for the validity of the phonetic radical-that is, whether the radical, when pronounced as a stand-alone character, actually is the pronunciation of the whole character. Thus, the frequency relationship for the value of both semantic and phonetic radicals is adaptive for reading. Less familiar characters are more likely to be correctly identified on the basis of their component radicals. Overall, however, the phonetic value of a compound is not high, estimated at about 38\% (Y. Zhou, 1978). (The estimate is higher with alternative statistical procedures.) Thus, neither semantic nor phonetic information in characters is highly reliable, although both are useful. For pronunciation, this means that the component radicals of characters are probably not reliable enough to support a systematic component approach to reading. We return to the role played by component radicals in the final discussion.

For comparisons with alphabetic systems, however, the most important fact about a phonetic radical is that it maps onto a syllable, never a phoneme. Whereas the $b$ in beech maps to the initial segment $(/ \mathrm{b} /)$ of the spoken word, a phonetic radical does not map to any segment of the syllable-morpheme represented by the character. Instead, it maps to a whole syllable that may (or may not) be the syllable-morpheme represented by the character. Thus, the critical departure from alphabetic writing is that Chinese writing does not reflect the segmental structure fundamental to alphabetic systems (Mattingly, 1987; Leong, 1997).

The implication of this fact is that phonological assembly, as it has been understood in alphabetic processes, is not possible for a single Chinese character. In alphabetic reading, assembly occurs as phonemes are activated by graphemes and "assembled" into a spoken syllable. In Chinese, no such assembly is possible because the graphemic units correspond to the whole syllables. Phonological assembly is actually possible for two- and three-character words, which are "assembled" from syllables. There is some evidence that this is how two-character words are identified (Tan \& Perfetti, 1999).

It is not surprising that a writing system with these properties encourages the hypothesis that reading is strictly a visual form-tomeaning process (e.g., Baron \& Strawson, 1976; M. J. Chen, Yung, \& Ng, 1988; Hoosain \& Osgood, 1983; Tzeng \& Hung, 1978; Wang, 1973; X. Zhou \& Marslen-Wilson, 1996). What is interesting is that, despite a writing system that disfavors it, the research suggests that phonology is very much involved in Chinese word reading. This research can be summarized as being consistent with the identification-with-phonology hypothesis. Applied specifically to Chinese, this hypothesis is that the phonological syllable is activated as part of character identification. Applied more generally to reading, this hypothesis is that the phonological units that are mapped by the writing system are activated as part of word identification.

\section{Word Identification With Phonology}

Experiments that use various paradigms have produced evidence for phonology in Chinese reading at several levels, from the character up through the sentence (e.g., Cheng \& Shih, 1988; Hung, Tzeng, \& Tzeng, 1992; Lam, Perfetti, \& Bell, 1991; Perfetti \& Zhang, 1991). Evidence showing phonology at the lexical level is consistent with the identification-with-phonology hypothesis (Perfetti \& Zhang, 1995; Perfetti \& Tan, 1998, 1999; Tan \& Perfetti, 1997), which places phonology as a constituent of word recognition (rather than a by-product). The same constituent characterization has been applied to alphabetic writing (Perfetti, Bell, \& Delaney, 1988). Phonology is activated at the moment of orthographic recognition - the point at which the identification system distinguishes a given graphic representation from other (similar and partly activated) representations. Thus, although graphic information initiates identification, phonological activation does not lag behind; rather it is part of a psychological moment of identification that is observable across writing systems. The difference among writing systems is that in an alphabetic system the elementary graphic units that initiate phonology correspond to phonemes. In a syllabic system, the elementary units correspond to spoken syllables; in Chinese, the elementary unit is also a spoken syllable that happens to be a morpheme, often a word.

The identification-with-phonology hypothesis has received considerable support in Chinese. Xu, Pollatsek, and Potter (1999) and Chua (1999) have independently reported evidence for phonological activation in a semantic categorization task. When asked to decide whether a character is a member of a prespecified semantic 
category, Chinese readers are slower and more inaccurate in rejecting a homophone of a category instance, a result parallel to what has been found in English (Van Orden, 1987). Although experiments with lexical decision tasks do not always produce phonological effects (X. Zhou \& Marslen-Wilson, 1996), such effects have been found under some circumstances (Weekes, Chen, \& Yu, 1998). Other tasks have also exposed phonology in Chinese reading. For example, in brief (but, critically, slightly above threshold) exposure with backward masking, a target word is better identified when a following mask is a homophone (Tan, Hoosain, \& Peng, 1995), similar to results in English (Perfetti et al., 1988). In semantic similarity judgments, two characters that are not similar in meaning but are homophones produce interference detectable in decision times and error rates (Perfetti \& Zhang, 1995; Zhang, Perfetti, \& Yang, 1999).

Tasks that involve meaning judgment (semantic categories, meaning similarity) are especially important because they require the reader to retrieve the semantic outcome of character identification rather than the phonological outcome. In meaning tasks, phonological processes show themselves primarily through interference. The results support the conclusion that phonology is rapidly available as part of character identification-rapidly enough to interfere with an apparently slower semantic process. It is also possible to observe phonological effects in noninterference situations where these can be designed. In a Stroop color-naming task, Spinks, Liu, Perfetti, and Tan (2000) found that characters that were homophones of color words produced facilitation when they were congruent with the color to be named as well as interference when they were incongruent. Results from these tasks cannot be taken to support the assumption that phonology mediates lexical access, for which a different experimental logic is needed (Tan \& Perfetti, 1997). However, these meaning experiments are critical for demonstrating the central idea that phonology is not bypassed in reading for meaning.

A different kind of experiment, the naming experiment, is helpful for exposing the time course of activation of lexical constituents. In the next section, we summarize critical results from naming experiments and describe a model of Chinese singlecharacter word naming. A focus on naming allows our analysis of Chinese reading to be compared with the explicit models of English reading that predict word naming (e.g., Coltheart et al., 1993; Seidenberg \& McClelland, 1989; Plaut et al., 1996). Of course, naming as the output of word identification requires phonology. Accordingly, our focus on naming is not about demonstrating the importance of phonology, which, as we have observed, already has been demonstrated even in meaning tasks. Instead, the goal is to explain how phonology interacts with other constituents of word representation in the course of reading aloud. This goal is part of a broader conceptualization of the general form of word representations, the lexical constituency theory, which we describe below.

\section{The Lexical Constituency Theoretical Framework}

In explaining the importance of phonology, we make the key assumption that word identification is the recovery of a phonological object and its associated nonphonological components. This is the fundamental obligatory process of reading. In the lexical constituency model, a word representation consists of three interlock- ing constituents (or variables): orthography (OR), phonology (PH), and semantics (SE). A word's identity is the specification of the values of these constituent variables: The word $\left(\mathrm{PH}_{\mathrm{i}}, \mathrm{OR}_{\mathrm{j}}, \mathrm{SE}_{\mathrm{k}}\right)$ is the word such that it has pronunciation $\mathrm{PH}_{\mathrm{i}}$, orthographic form (spelling) $\mathrm{OR}_{\mathrm{j}}$, and meaning range $\left(\mathrm{SE}_{\mathrm{k}}\right)$. We use the term meaning range because we assume that, for a single word, meaning is not deterministic in the same sense that form is. The absence of any one of these $(\mathrm{PH}, \mathrm{OR}, \mathrm{SE})$ values results in an underspecified identity. A failure of full constituent specification can lead to identification failures of various types, depending on the extent of unique OR and PH values in the system. (Shared SE values are true synonyms and actually have little consequence for receptive [comprehension] processes, although they do have consequences for production processes.)

The assumption that words can be represented by orthographic, phonological, and semantic components is not new. Distributed representation triangle models (Plaut et al., 1996; Plaut \& Booth, 2000) explicitly represent these three levels without having a level of lexical representation. Symbolic dual-route models (Coltheart et al., 1993; Coltheart et al., 2001) also represent these components. Although the constituency framework is theoretically neutral among various possible implementations, our description of it relies on a symbolic system. Thus, we emphasize that word representations comprise constituent identities. We also emphasize that the constituency framework is universal, not language or writing-system dependent. In any writing system, it is the representation of the word that is at issue, and the specification of a value on each of the variables (the constituents) provides the identity of the word as it is represented in an idealized mental lexicon. The process of identification becomes one of specifying constituents. In processing terms, written word identification entails the retrieval of a phonological form and meaning information from a graphic form.

For English, some of the consequences of this formulation can be seen in cases of form and meaning ambiguity.

1. When a homophone is spoken, the word is unidentifiable. It is specified on (PH) only. Thus, in English, /nayt/ can be either (/nayt/, night, [SE1]) or (/nayt/ knight, [SE2]).

2. When a homophone is written, its identity is specified: $\mathrm{PH}+\mathrm{OR} \supset \mathrm{SE}$. Thus $n-i-g-h-t$ uniquely specifies /nayt/ as (/nayt/, night, SE1]).

3. When a homograph is written, its identity fails. Thus $b$ - $a$-s-s fails to identify (/bæs/, bass, SE1-fish) as opposed to (beys/, bass, SE2-music).

4. When a homograph is pronounced, its identity is specified.

5. When a polysemous word is encountered, identity fails whether it is spoken or written, for example, $s-p-r-i-n-g$ (/spring/, spring, SE1-season) versus (/spring/, spring, SE2-coil).

This analysis of word identification as constituency specification has some implications for descriptions of word processing. The most important one is that because a phonological form is a constituent of word identity, word identification entails the re- 
trieval of a phonological form or an implicit pronunciation. Notice that this is not the usual issue of whether phonology is "prelexical," preceding access to meaning, or "postlexical," following access to meaning. It is rather that phonology is a constituent of the identified word, so it is part of what is identified. The timing of events that yield the constituents is another matter. Failures at word reading can be characterized as incomplete retrievals (failing to yield one of a word's constituents) or asynchronous retrievals (yielding a constituent in an untimely manner). However, the cause of these retrieval failures can lie not in processes but in word knowledge that is incomplete or unreliable, failing to give a full specification of one or more of a word's constituents. The lexical quality hypothesis (Perfetti \& Hart, 2001) postulates that reading skill is the extent to which a reader's lexicon is characterized by fully specified lexical representations (orthographic form, phonological form, and meaning).

A second implication is that meaning processing is less specified at the word level than is form processing, leading to temporal differences favoring phonological processing over meaning processing. In their dynamic systems approach, Van Orden and Goldinger (1994) have also proposed this priority of phonology over meaning. In our approach, the priority of phonology has a specific origin in the ways that languages and writing systems work. This origin is the determinacy principle: At the word level, form-form relationships are very reliably specified in most writing systems, whereas form-meaning relations are not. At the word level, a given orthographic form usually corresponds to a single phonological form. In English, the examples such as bass (one orthographic form, two phonological forms, two meanings) are actually quite rare compared with the examples such as spring (one orthographic form, one phonological form, two meanings). Given an orthographic input, a word's pronunciation is more determined than its meaning - in Chinese as well as in English. It is important to note that this linking of Chinese and English is possible because the determinacy principle holds not at the grapheme-phoneme level but at the lexical level.

\section{A Computational Version of the Lexical Constituency Model}

With this conceptual basis for the lexical constituency model (see also Perfetti \& Tan, 1998, 1999), we turn to explicit model development. In this section, we describe a computational instantiation of the lexical constituency model that can capture the time course of constituent effects in naming. The model assumes that orthographic, phonological, and semantic constituents specify word identity. Further, on the basis of the determinacy principle, it assumes that formform relationships are rapidly available so that phonological information might be quickly retrieved given a graphic input. The test of the model is its simulation of primed naming results from Perfetti and Tan (1998), which we summarize in the next section.

\section{The Time Course of Constituent Information in Primed Naming (Perfetti \& Tan, 1998)}

In a primed naming experiment, Chinese speakers were presented with a brief prime character followed by a target character at variable stimulus onset asynchrony (SOA). The primes were of four types in their relation to the target. Graphic primes were visually similar to the target (but without phonological or meaning similarity); in most cases, this similarity resulted from shared features between target and prime. Phonological primes were homophones with no shared radicals and no graphic similarity. Semantic primes were related in meaning without graphic or phonological similarity. Unrelated primes had no relation with the targets, serving as a baseline. (Another baseline condition used the symbol \# instead of a character prime. These two baseline conditions produced nearly identical naming times.) The SOA between prime and target onset varied between $43 \mathrm{~ms}$ and 115 ms. The important results are the priming effects across SOA, as is shown in Figure 1.

The general pattern of priming effects shows graphic, phonological, and semantic information, in that temporal order, affected target naming. This ordering suggests two interesting results that

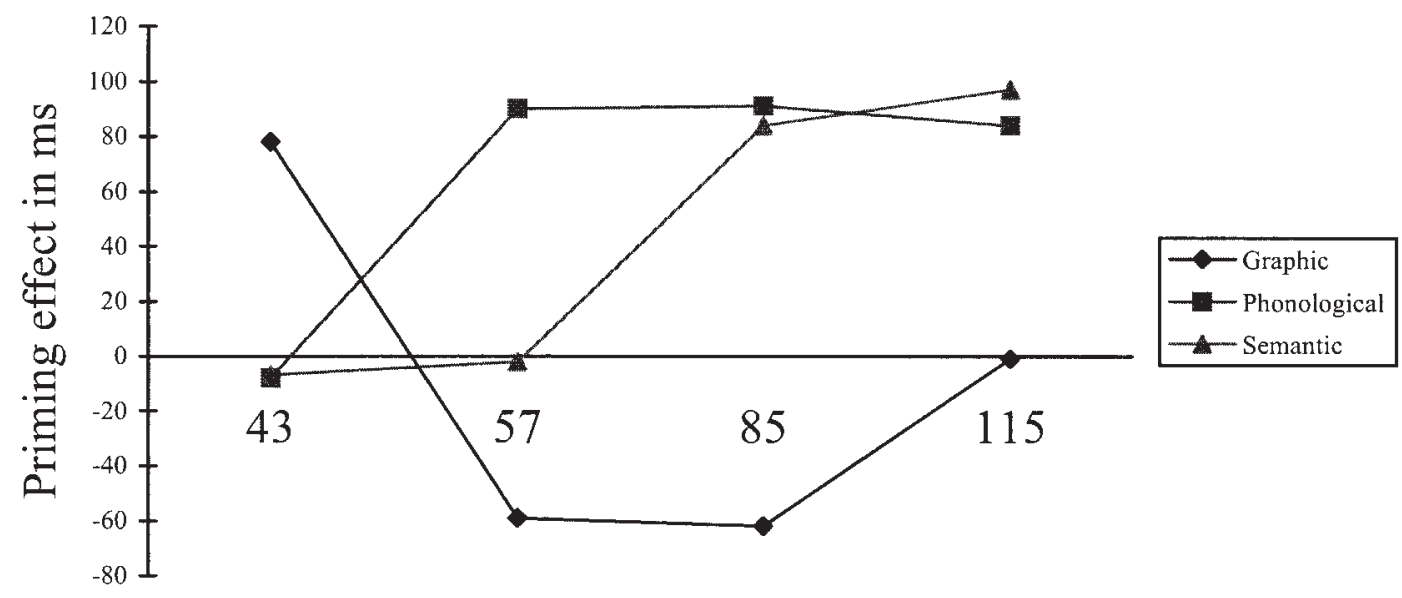

\section{Prime-target SOA in ms}

Figure 1. The time course of priming effects for graphic, phonological, and semantic primes relative to unrelated character prime baseline (based on data from Perfetti \& Tan, 1998). SOA = stimulus onset asynchrony. 
support the assumption that priming effects reflect the availability of the information sources that are manipulated in the prime-target relationships. First, graphic information begins the identification process and is the first to show a priming effect. Second, phonological information precedes semantic information in primed naming, which is consistent with the task demands of producing a phonological output, although it may be observed in meaning tasks as well under some circumstances (Perfetti \& Zhang, 1995).

In addition to these more straightforward results, there is a nonobvious result visible in Figure 1. The effect of graphic similarity was nonmonotonic over SOA. The initial effect was facilitation at 43-ms SOA, but by $57 \mathrm{~ms}$ graphic similarity produced inhibition before it finally stabilized at the longest SOA, $115 \mathrm{~ms}$. Also interesting is that phonological priming became facilitative just at the point at which graphic similarity became inhibitory. Although comparative writingsystem data with a comparable task are scarce, this oscillation effect, as far as we know, has not been observed in alphabetic reading. (Indeed, our prediction is that it cannot occur in alphabetic writing.) The general explanation for the oscillation is that the initial facilitation comes from the activation of lexical constituents (form and meaning features) in the prime that turn out to be present in the target. The subsequent inhibition arises as the prime itself becomes identified as a character, thus competing with the target. However, at this level of generality such an explanation fails to explain why other primes (which, after all, were also characters that could compete with the target) did not produce a similar inhibition. This lack of inhibition was true not only for the phonological and semantic primes, but also for the baseline unrelated primes that could be compared with \# primes. So something more is needed, and the model that we describe below provides it.

Finally, another result, which is not visible in Figure 1, is the comparison between two kinds of semantic primes: vague meaning and precise meaning. We defined this contrast by a rating scale in which Chinese speakers rated single characters as relatively vague in meaning versus relatively precise in meaning. Although this vagueprecise contrast does not lend itself to a single underlying semantic analysis, vague meaning includes both ambiguity and context-dependence-in general, it is the perception that, by itself, a character's meaning is uncertain. This vagueness variable has been shown to influence identification in brief exposure paradigms (Tan et al., 1995). What was interesting in the Perfetti and Tan experiment was that this semantic variable was independent of the prime type-graphic, phonological, and semantic primes all came in two types: precise and vague. Yet the effect of semantic vagueness was restricted to semantic primes: Priming was earlier for precise-meaning primes than it was for vague-meaning primes; for phonological and graphic primes, prime meaning was irrelevant. This suggests a functional independence between meaning and form features in primed naming. The graphic and phonological priming, which are early relative to semantic priming, reflect pure form effects.

The results are consistent with the conceptual description of word identification given by the constituency model, but this description is at a very general level. The question is whether some of the important details of the time course of primed naming effects can be explicitly modeled.

\section{The Implemented Lexical Constituency Model}

In this section, we describe the current implementation of the model, designed with a limited scope to recognize 204 characters and applied to primed character naming. Its aim is to expose the functioning of orthographic, phonological, and semantic constituents in character identification.

The basic graphic unit in the model is a radical, one of the 623 Bujian (radicals) that combine to produce the Chinese character vocabulary. Our model contains 146 binary input units, a quantity determined by the number of binary units for each radical, the number of radicals and their spatial distribution in a character, as is explained below.

The model is a network of linked units of orthographic, phonological, and semantic constituents across which activation spreads. Its input units are radicals and the spatial relationship between the radicals. The radical input and the phonological levels of the model can be considered distributed representations, whereas the orthographic and semantic representations can be considered localized representations. Connection weights are fixed rather than "trained," reflecting the relationships between and within levels that are inferable from research or from convenient weak assumptions. ${ }^{1}$ An illustration of the model is presented in Figure 2, and its main features are described below.

\section{Input (Radical) Level}

Among 146 input units, 144 units represent radicals, the basic components of Chinese characters, whereas two units represent the four possible spatial relationships between radicals within a Chinese character. A radical is specified by the values on 16 binary codes. The actual subset of codes used (from the $2^{16}$ possibilities) match those used for each radical in the Chinese National Character Component Standard for Information Processing (Publication Code GB2312-80). This scheme of 16 binary codes is replicated over nine slots, ensuring that any character with up to nine radicals, the maximum number in the National Standard Chinese Character set (Publication Code GB2312-80), can be represented. Each radical slot is assigned according to the conventions for character composition (e.g., left radical, then right radical). With radical slots to represent the radicals themselves and spatial slots (explained below) to represent their spatial relationships within the character, this system is sufficient to represent the shared radical structure between almost any two Chinese characters. ${ }^{2}$ The radical units $r_{i}(i=1,2, \ldots, 146)$ have a value of -1 or 1 for a given character. (See Figure 3.)

The spatial arrangement of radicals within a character was represented by two of the 146 orthographic units. Radicals within a character have one of four general spatial relationships as illustrated below:

\footnotetext{
${ }^{1}$ For example, a specific orthographic unit (a character) connects with weight 1 to phonological units (onsets, rhymes, and tones) that are part of the pronunciation and with weight 0 for all others. This assumes that phonologically similar onsets, for example, are not activated by a character. This is convenient and weak in the sense that it has little consequence in the simulations of interest. Of course, it could matter for other problems, such as errors made in production. As is the custom in this class of models, the values of the weights represent the strength of connections between units whereas their polarity represents excitatory $(+)$ or inhibitory $(-)$ connections.

${ }^{2}$ Use of the National Standard binary code allows the replication of our radical input by others. For simplicity, the model does not include a stroke level, which could be considered an initiating input level connected to a radical level. Taft and Zhu (1997) describe a model that includes strokes as one of three hierarchical levels, the other two being radicals and characters.
} 


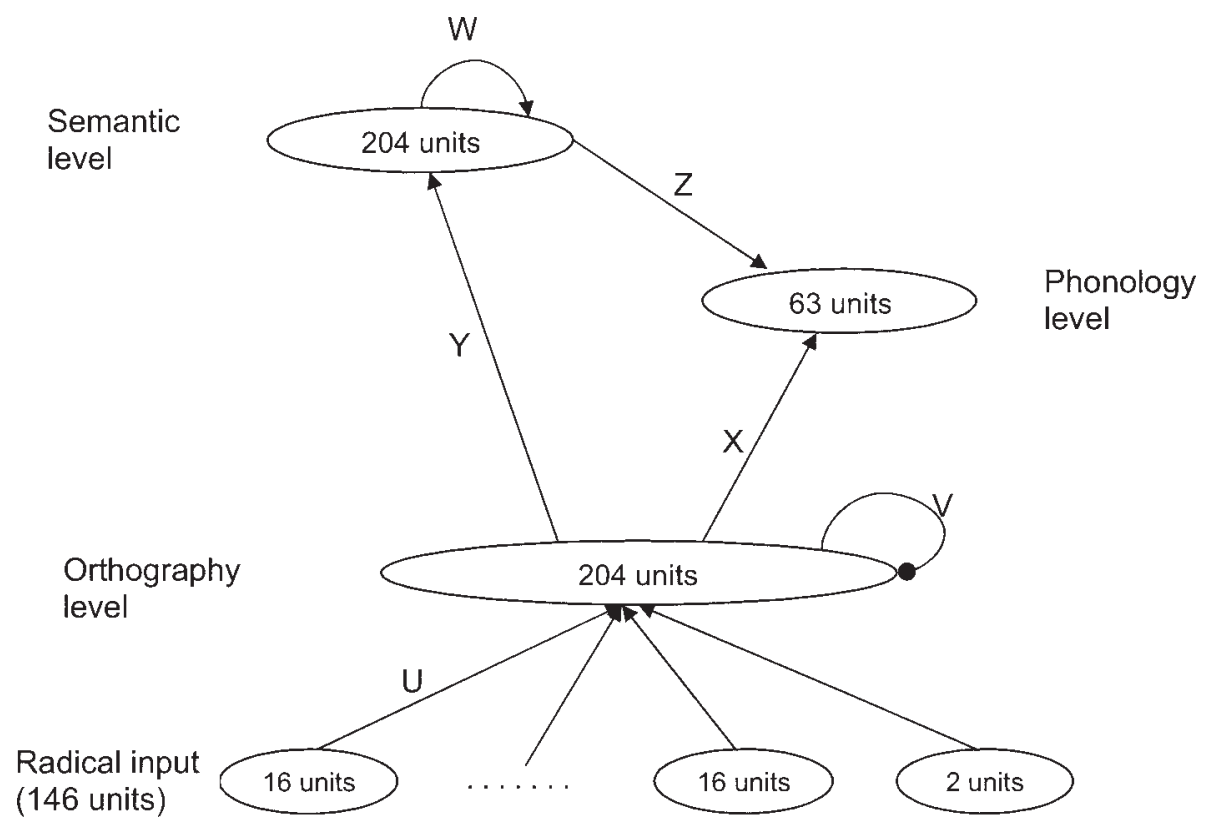

Figure 2. The lexical constituency model in schematic form. See text for further explanation.

Left-right 扰; Top-Bottom 艺;

Closed outside-inside 国; Open outside-inside 同.

These four possibilities, which are fully represented by two binary units, include not only all possible two radical characters, but in effect also generalize to characters of three or more radicals. ${ }^{3}$

\section{Connections Between Radical Level and Orthographic Level}

The radical level is fully connected to the orthographic level, sending activation to the 204 character units along hand-adjusted weighted connections. Each radical slot sends activation to any character in the orthographic level that contains that radical written in the sequence specified in the radical slot. The connection weights reflect the relative (to other radicals) contribution of the given radical to the character composition. Thus, a given radical sends more activation to a one-radical character (for which it comprises $100 \%$ of the graphic units) than to a two-radical character (for which it provides $50 \%$ of the graphic units). Furthermore, an activated radical slot sends no activation to any character that does not contain that radical. The connection weights are as follows: (See Equations 1 and 2 in the simulation section for the computation.)

$u_{i j}=\left\{\begin{array}{cc}1 / 16 & \text { unit } i=1 \text { in character } j \\ -1 / 16 & \text { unit } i=-1 \text { in character } j \\ 0 & \text { unit } i \text { does not exist in character } j\end{array}\right.$

$$
i=1,2, \ldots, 144, j=1,2, \ldots, 204
$$

$u_{i j}=\left\{\begin{array}{cc}1 / 2 & \text { unit } i=1 \text { in character } j \\ -1 / 2 & \text { unit } i=-1 \text { in character } j\end{array}\right.$

$$
i=145,146, j=1,2, \ldots, 204 .
$$

\section{Orthographic Level}

The orthographic level is a localized representation of the graphic form of characters. In the current implementation, each unit of this level represents one of 204 characters. The activation value of each orthography unit $o_{i}(i=1,2, \ldots, 204)$ is between 0 and 1 .

\section{Connections Within the Orthographic Level}

There are negative (inhibitory) connections between each pair of orthographic units, reflecting competition between characters at the input level. The connection weights are set as follows:

$$
v_{i j}=\left\{\begin{array}{cc}
0 & i=j \\
-1 & i \neq j
\end{array} \quad i=1,2, \ldots, 204, j=1,2, \ldots, 204\right.
$$

\section{Phonological Level}

Phonology is a distributed representation that is implemented with the Chinese national standard Pinyin system. Each syllable is coded across 3 units-onset, vowel, and tone. The model represents the syllables of Mandarin, for which 23 onsets, 34 vowels,

\footnotetext{
${ }^{3}$ When there are more than two radicals, the number of possible spatial relationships naturally increases. However, the major multiple relations are captured by our coding system. For example, a three radical character of the type ${ }^{A} \mathrm{C}$ can be represented as a left-right relation. Because for any three given radicals, $\mathrm{A}, \mathrm{B}$, and $\mathrm{C}$, there is no combination such that both ${ }_{\mathrm{B}}^{\mathrm{A}} \mathrm{C}$ and $\mathrm{ABC}$ are real characters, not all mathematically possible combinations have to be represented. Thus, our simplified coding system is sufficient to represent all common characters without spatial relation confusion.
} 


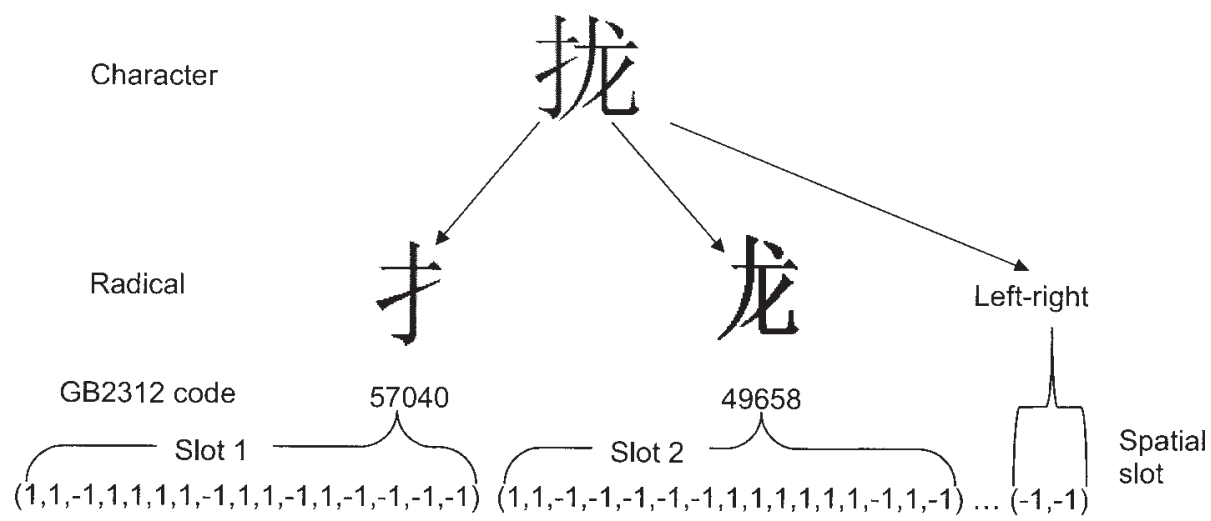

Figure 3. An example of how the model represents a two-radical Chinese character by binary units. The numbers under the two radicals correspond to the GB2312 National Standard Chinese codes. The binary units at the bottom are the first two radical slots (16 units in each). The remaining seven radical slots are not shown because they are "empty" (all units at -1 ). The final spatial slot ( 2 units) specifies that these radicals have a horizontal layout.

and five tones are sufficient. With the addition of 1 additional unit to represent null onsets, the phonological level consists of 63 units. Because this level is a distributed representation, there are no within-level linkages, in contrast to the orthographic and semantic levels. Each phonology unit $p_{i}(i=1,2, \ldots, 63)$ has an activation value between 0 and 1 .

\section{Semantic Level}

Character meaning is a localized representation of 204 units, each corresponding to a unique meaning of a single character. Meaning precision is represented by connection weights between the orthographic and semantic levels. The semantic level currently does not represent meaning components. Each semantic unit $s_{i}(i=$ $1,2, \ldots, 204)$ has an activation value between 0 and 1 .

\section{Connections Within the Semantic Level}

Two related meanings are connected at a weight of 0.2 , arbitrarily reflecting the assumption that semantic relations are not perfectly determinate, hence much less than 1 . Other connections are set at zero. The weightings are as follows:

$w_{i f}=\left\{\begin{array}{cc}0.2 & \text { if character } i \text { is related to } j \text { in meaning } \\ 0 & \text { otherwise }\end{array}\right.$

$$
i=1,2, \ldots, 204, j=1,2, \ldots, 204 .
$$

\section{Connections Between Orthography and Phonology}

Each orthographic character unit has three connections with weights of 1: one to the onset, one to the vowel, and one to the tone. All other connection weights were set at zero. The connection weights are set as follows:

$x_{i j}=\left\{\begin{array}{cc}1 & \text { character } i \text { has } j \text { as onset, vowel or tone } \\ 0 & \text { otherwise }\end{array}\right.$

$$
i=1,2, \ldots, 204, j=1,2, \ldots, 63 \text {. }
$$

\section{Connections Between Orthography and Semantics}

A precise-meaning character is connected to one semantic unit with weight 1 . A vague-meaning character connects to one semantic unit at weight 0.99 and to all other 203 semantic units at randomly distributed weights between 0 and 0.01 .

$$
y_{i j}=\left\{\begin{array}{cc}
0.99 & i=j \text { and } i \text { is a vague meaning character } \\
\operatorname{random}(0,0.01) & i \neq j \text { and } i \text { is a vague meaning character } \\
1 & \begin{array}{l}
i=j \text { and } i \text { is a precise meaning character } \\
i \neq j \text { and } i \text { is a precise meaning character }
\end{array} \\
& i=1,2, \ldots, 204, j=1,2, \ldots, 204 .
\end{array}\right.
$$

\section{Connections Between Semantic and Phonological Levels}

Each semantic unit is connected with each of its three phonological units (onset, vowel, and tone) at weight 1. All other connection weights are zero.

$$
\begin{aligned}
z_{i j}=\left\{\begin{array}{rr}
1 & \text { semantic } i \text { has } j \text { as onset, rhyme or tone } \\
0 & \text { otherwise }
\end{array}\right. \\
\qquad \quad i=1,2, \ldots, 204, j=1,2, \ldots, 63 .
\end{aligned}
$$

\section{Formal and Semantic Similarity Representation}

A key goal of the model is to represent similarity along graphic, phonological, and semantic dimensions, implemented as follows: Graphic similarity results from shared radicals. A given radical input activates a cohort of similar (same radical in same position) characters. Phonological similarity results from shared phonological activation patterns. Homophones have identical patterns; lower levels of similarity result from shared onsets, vowels, or tones. Related meanings arise from connections with 0.2 weights between the semantic units of characters that are semantically related. 


\section{Threshold}

Each unit in all three levels has a threshold below which the unit cannot send output to another level. For example, below threshold, orthographic units send no output to phonology. Reaching the threshold of a target character can be facilitated by the presentation of an orthographically similar prime. The threshold levels were set arbitrarily at 0.8 for all units. The threshold was implemented in the model by a threshold function

$$
\mathrm{T}(x)= \begin{cases}1 & x \geq 0.8 \\ 0 & x<0.8\end{cases}
$$

\section{A Simulation of Time Course Data from Perfetti and Tan} (1998)

The simulation was carried out with prime-target relations defined by graphic, phonological, and semantic similarity as is illustrated in Table 1.

In the simulation, 146 binary codes of a character are presented to the input units. The input units were grouped into 10 slots that send activation to orthographic units. The input to orthographic unit $j$ received from slot $i$ is

$$
s_{i j}=\left\{\begin{array}{ll}
1 & \mathbf{R}_{i} \mathbf{U}_{i j}=1 \\
0 & \mathbf{R}_{i} \mathbf{U}_{i j}<1
\end{array} \quad i=1,2, \ldots, 10, j=1,2, \ldots, 204,\right.
$$

where $\mathbf{R}_{i}$ is a 16 or 2 digit column vector of input units in slot $i$ and $\mathbf{U}_{i j}$ is a row vector of the connection weights between the 16 or 2 units in slot $i$ and orthographic unit $j$.

The input from nine radical slots are summed and multiplied by the input from the position slot (which contains two position units), and divided by the number of radicals in the presented character, creating an expression with maximum value 1 .

$a_{j}=s_{10 j} \sum_{i=1}^{9} s_{i j} /($ radical number of character $j)$

$$
j=1,2, \ldots, 204 \text {. }
$$

A is a column vector to denote the inputs to 204 orthographic units, and $\mathbf{O}, \mathbf{P}$, and $\mathbf{S}$ are three column vectors to denote the activation value of orthographic, phonological, and semantic units. $\mathbf{U}, \mathbf{V}, \mathbf{W}, \mathbf{X}, \mathbf{Y}$, and $\mathbf{Z}$ denote the connection weights matrixes (see Figure 2). $T$ is the threshold function. The activation values at time point $t+1$ are

Table 1

Examples of Prime-Target Relations in the Simulation

\begin{tabular}{lll}
\hline \multicolumn{1}{c}{ Condition } & \multicolumn{1}{c}{ Prime } & \multicolumn{1}{c}{ Target } \\
\hline Graphical similar & 拢(/long/3, collect) & 扰 $(/ \mathrm{rao} / 3$, disturb $)$ \\
Homophone & 芯 $(/ \mathrm{yi} / 4$, art $)$ & 易 $\mathrm{q}(/ \mathrm{yi} / 4$, easy $)$ \\
Semantic related & 酒 $/ / \mathrm{jiu} / 3$, wine $)$ & 菜 $(/ \mathrm{cha} / 2$, tea $)$ \\
\hline
\end{tabular}

$$
\begin{aligned}
& \mathbf{O}(t+1)=\mathbf{O}(t)+\{\mathbf{A}+\mathbf{T}[\mathbf{O}(t)] \mathbf{V}-\mathbf{O}(t)\} \times 0.2 \\
& \mathbf{P}(t+1)=\mathbf{P}(t)+\{\mathbf{T}[\mathbf{O}(t)] \mathbf{X}+\mathbf{T}[\mathbf{S}(t)] \mathbf{Z}-\mathbf{P}(t)\} \times 0.05 \\
& \mathbf{S}(t+1)=\mathbf{S}(t)+\{\mathbf{T}[\mathbf{O}(t)] \mathbf{Y}+\mathbf{S}(t) \mathbf{W}-\mathbf{S}(t)\} \times 0.05
\end{aligned}
$$

To simulate a trial of the primed naming experiment, a prime character is presented to the input units for 0 to 29 processing cycles. Then, the input is switched to the target character. When the number of processing cycles of the prime is equal to or greater than 20 , the activation values of all orthographic units are reset to 0 , and the retained activations of phonological units are limited to less than or equal to 0.2 ; for fewer processing cycles (shorter SOAs), the activation values of orthographic units established by the prime are retained as the target activation begins. After the switch to target input, the model iterates until one onset, one rhyme, and one tone unit in the phonological level reach the threshold of 0.8. These three units are the model output of this trial. The number of the final processing cycle is recorded and treated as the reaction time of the trial. ${ }^{4}$

Certain assumptions of the model-especially a threshold setting for orthographic units - turn out to be important in simulating Perfetti and Tan's (1998) time course results for graphic, phonological, and semantic priming effects. Of special interest are (a) the oscillation effect for orthographically similar primes and (b) the rise of phonological priming, coincident with orthographic inhibition. The simulation of these effects is shown in Figure 4. (The $x$-axis shows processing cycles; the $y$-axis shows priming effects as processing cycles relative to the control condition; effects $<0$ reflect inhibition.)

What the simulation captures clearly is the pattern of graphic oscillation, with the onset of graphic inhibition coinciding with the onset of phonological facilitation. At short SOA, the simulation produced facilitation from graphic primes through nine processing cycles (SOAs), at which point interference began. The facilitation occurs because visually similar orthographic units are activated by the same radical; so with a graphic prime, the activation level of the target, which shares a radical with the prime, is nearer to threshold than it would be otherwise; hence, graphic facilitation is first. Importantly, this facilitation has occurred without the orthographic unit of prime character itself reaching threshold.

When an orthographic unit does reach threshold, it sends its activation to the phonological unit immediately, allowing a phonological priming effect if the activated unit happens to be a homophone-that is, a pronunciation shared with the target. But because it has reached threshold, the orthographic unit itself is available to compete with the target when they are not homophones: It has sent activation to an incompatible phonological output. The appearance of the target keeps the prime orthographic unit activated for a period of time when they are graphically similar because of the radical shared by the prime and target orthographic units. The net result is competition that delays the identification of the target. This competition does not occur with a prime that is not graphically similar to the target because it does not share a radical with the target; so the onset of the target

\footnotetext{
${ }^{4}$ MATLAB (MathWorks, Natick, MA) codes for simulation are available for downloading at http://www.pitt.edu/ liuying/simulation.zip.
} 

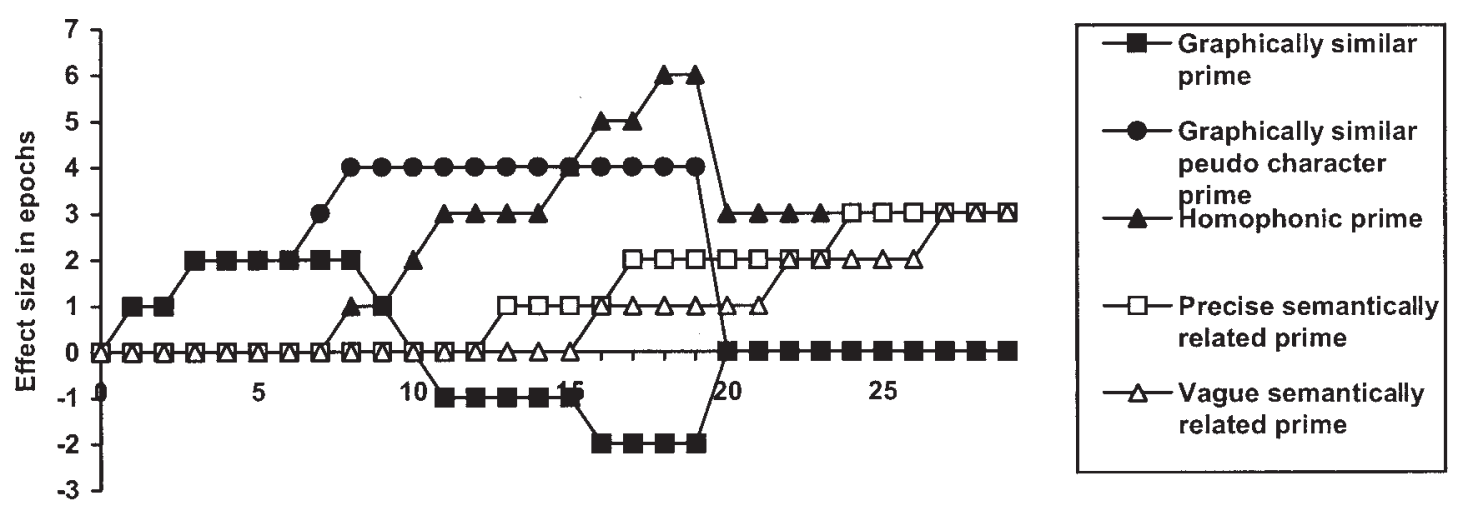

SOA in epochs

\begin{abstract}
Figure 4. The lexical constituency model's simulation of the time course of graphic, phonological, and semantic priming effects from Perfetti and Tan (1998). Averaged graphic, phonological, and precise and vague semantic priming effects of 12 stimuli are shown relative to an averaged baseline (12 unrelated character primes) in terms of processing epochs. Thus, facilitation is a positive effect (up), and inhibition is a negative effect (down). In addition, the effect of one graphically similar pseudoword is simulated. A character prime that is visually similar to the target produces facilitation, and then inhibition is time-locked to phonological facilitation. A pseudocharacter prime that is visually similar to the target produces only facilitation. $\mathrm{SOA}=$ stimulus onset asynchrony.
\end{abstract}

immediately terminates further input to the prime's orthographic unit.

When the duration of a prime is long enough, a human subject can become aware that the prime and target are different characters and direct attention to target processing. This allows the end of inhibition from the prime. The simulation captures this end of inhibition through a "reset" procedure of the orthographic unit at 20 processing cycles, which is longer than the number of cycles needed to reach orthographic threshold but shorter than what is needed for the character to be pronounced. This causes graphic effects to end at the longest SOA $(115 \mathrm{~ms})$ in a behavioral experiment, while phonological and semantic effects continue.

Thus, two important form priming effects are simulated successfully within the same processing time line. After a brief period of prethreshold graphic facilitation, graphic inhibition and phonological facilitation simultaneously emerge.

Semantic priming results from an orthographic unit that reaches threshold and sends its output to its semantic unit, which can activate related orthographic units-especially the target. However, this priming is not as rapid as phonological priming because the link between a target's semantic unit and that of a related prime is not as strong as the link between the target's orthographic unit and its phonological units.

This difference in semantic and phonological linkages is an implementation of the assumption of differential determinacy of semantics and phonology, given an orthographic form. It might equivalently be characterized as capturing the idea that whereas forms can be identical (homophones), meanings cannot. At the implementation level, these two related assumptions cannot be distinguished.

The model also simulates the meaning precision effect-faster priming for precise primes only for meaning-related primes (and not for graphic and phonological primes, which also vary in meaning precision). This is because the system does not care about semantics at the phonological or graphic level; a vague homophone prime is not different from a precise homophone prime. But at the semantic level, precision is represented directly in the distribution of meaning activation across the semantic units.

\section{An Additional Test of the Model}

An important empirical result simulated by the model is the temporal pattern of very brief orthographic facilitation followed by inhibition (Perfetti \& Tan, 1998). The facilitative component of this orthographic effect may be fragile. H.-C. Chen and Shu (2001) report a study identical in critical respects to Perfetti and Tan (1998) in which they fail to find facilitative priming by a graphically similar prime at $43 \mathrm{~ms}$ and $57 \mathrm{~ms}$. However, other results are consistent with the pattern of Perfetti and Tan. For example, Shen and Forster (1999) found graphic facilitation in naming (as well as in lexical decision) with $50 \mathrm{~ms}$ of exposure. For another, the pattern of graphic facilitation followed by inhibition was observed in lexical decision by Feldman and Siok (1999, Experiment 3). In the condition of their experiment most closely related to that of Perfetti and Tan, prime-target pairs that shared radicals (without transparent meaning relations) showed facilitation at $43 \mathrm{~ms}$ but inhibition at $243 \mathrm{~ms}$. In addition, Ding, Peng, and Taft (2004) reported facilitation in lexical decision at $43 \mathrm{~ms}$ for prime radicals in the same position as the target. Finally, Pollatsek, Tan, and Rayner (2000) carried out a naming experiment with parafoveal priming through the use of eye-movement contingent display changes. Although their main result was a facilitative effect for a phonological prime, they also found a facilitative effect for a prime sharing a radical without the same pronunciation, an effect that 
must be attributed to radical-level orthographic priming. ${ }^{5}$ Thus, the finding of graphic facilitation is replicable. ${ }^{6}$

The model makes a prediction relevant for the temporal patterns of graphic and phonological effects that can be tested directly. Important to the model's ability to simulate the graphicphonological oscillation pattern is the role of the orthographic level and its relation to the radical input level. The important assumption is that both phonology and similarity-based orthographic competition arise from an orthographic character when its threshold is reached. An implication of the model, then, is that the graphic interference effect requires character-level competition based on shared radicals rather than competition between visually similar radicals, which are not connected in the model. Because it is character-level competition that is critical, the model also implies that competition should not occur for a pseudocharacter prime, even if it shares a radical with the target character. An experiment testing this prediction is reported briefly below.

\section{Rationale}

If, instead of a real Chinese character, a prime is a pseudocharacter composed of real radicals in legal positions, then radicalbased orthographic priming should occur without a later stage of character-based orthographic inhibition. This is because the pseudocharacter has no orthographic unit representation. In the model, its presentation as a prime will activate a cohort of characters that share its radical(s). When the target turns out to be one of these, its identification will be facilitated through a prior threshold lowering produced by the radical input. However, no character reaches threshold during the prime exposure, so there is no activation of a graphically similar orthographical unit to compete with the target. Thus, we carried out an experiment in which real characters and pseudocharacters served as primes, with SOAs of $57 \mathrm{~ms}$ to $143 \mathrm{~ms}$.

\section{Method}

Participants and design. Seventy-two undergraduate and graduate students from Beijing Normal University participated in the experiment for payment. All were native Mandarin speakers. Each group of 24 participants had one SOA: $57 \mathrm{~ms}, 86 \mathrm{~ms}$, or $143 \mathrm{~ms}$. Eighteen target characters were used with three different primes: an orthographically similar real character, an orthographically similar pseudocharacter, and a real-character control prime, unrelated to the target. ${ }^{7}$ The average number of strokes and radicals were matched across all primes for a given target. The average character frequency of real character and control primes was also matched. Targets appeared with each prime for each participant. Accordingly, the order of presentation was balanced so that each initial occurrence of a target was equally likely to be primed by one of the three prime types. Within blocks of 18 trials, the prime-target pairings were randomized with the constraint that 6 of each type would occur.

Procedure. Each participant viewed 72 character pairs, 18 pairs for each prime condition and 18 pairs of fillers. Each trial began with the presentation of a fixation cross at the center of the screen for $500 \mathrm{~ms}$. After the offset of the fixation, a prime was immediately presented for $57 \mathrm{~ms}$, $86 \mathrm{~ms}$, or $143 \mathrm{~ms}$ and was immediately followed by a character target. The target remained on the screen until participants made a naming response. Participants were informed that a very brief exposure of a first character would be followed by a second character, and that their task was to pronounce the second character as quickly and as accurately as possible. They were not told about any relationships that might exist between the two characters.

\section{Results}

Latencies for correctly named words and error results are shown in Table 2. (The data trimming followed a two-step procedure. All the naming latencies greater than $1,500 \mathrm{~ms}$ and less than $200 \mathrm{~ms}$ were first ignored; then the naming times more than two standard deviations from the mean were eliminated.) The general pattern of priming effects is as predicted. At the shortest SOA, a graphically similar character showed a 21-ms facilitative priming effect. At the intermediate SOA, this effect disappeared and was inhibitory at the longest 143-ms SOA. A graphically similar pseudocharacter produced only facilitation at the shortest two SOAs before disappearing at $143 \mathrm{~ms}$. At 54-ms SOA, $F(22,1)=21.52, p<.01$; and at 86-ms SOA, $F(23,1)=15.46, p<.01$. The character inhibition effect is marginally reliable in latency at $143 \mathrm{~ms}, F(23,1)=3.63$ $p=.07$, and appears in error rates at $86 \mathrm{~ms}^{8}$

\section{Discussion}

The experiment produced the predicted pattern of facilitation followed by inhibition for visually similar character primes, as was reported by Perfetti and Tan (1998). Equally important, it produced a simple pattern of facilitation only for a pseudocharacter prime, as predicted by the model. That the character inhibition effect in latency did not reach the conventional $\alpha=.05$ standard for Type 1 errors is less relevant than is the clear pattern of convergence with the results of Perfetti and Tan (1998) and the observance of facilitation effects for pseudocharacters. Indeed the effect questioned by H.-C. Chen and Shu (2001) is not the graphic interference but the earlier facilitation. In effect, this pattern rep-

\footnotetext{
${ }^{5}$ The contingent display change procedure allows very brief viewing of the prime in the parafovea. On noticing the prime, readers move their eyes to its location, where the target has replaced the prime. Assuming from the estimates by Pollatsek et al. (2000, p. 612) that a saccade takes at least 30 $\mathrm{ms}$, one can take $30 \mathrm{~ms}$ as the lower boundary approximation of the time for which the prime is viewable prior to the target.

${ }^{6}$ As with any null result, the failure of H.-C. Chen and Shu (2001) to find a brief window of graphic facilitation could arise from any of a number of factors. Because graphic similarity provides the basis for both facilitation (similar form) and interference (similar form, different pronunciation), the direction of graphic effects may be very sensitive to timing and viewing conditions if a brief period of facilitation prior to the onset of inhibition is to be detected.

${ }^{7}$ The unrelated character prime serves as a baseline against which to measure facilitative and inhibitory effects. The possibility that an unrelated character prime could actually be inhibitory was considered in the primed naming study of Perfetti and Tan (1998). They used a second baseline condition, the nonlinguistic symbol \#, and found no difference between this baseline and the unrelated character prime. Thus we used only the unrelated character baseline in the present experiment.

${ }^{8}$ Error rates were too low to take as the major expression of priming effects. However, they showed the expected pattern of decreasing with SOA and being lower for pseudocharacters than for real characters at all SOAs, including $54 \mathrm{~ms}$, where the characters produced shorter latencies than did the pseudocharacters. The error rate difference at $54 \mathrm{~ms}$ could raise a concern about a possible speed-accuracy tradeoff. However, it may instead reflect variability in orthographic thresholds across characters and subjects. Errors are possible whenever a prime character is activated to its threshold. Thus, error free trials show the graphic facilitation effect, whereas occasional errors reflect a prime that has reached its threshold.
} 
Table 2

Mean Naming Latencies (in Milliseconds) and Error Rates for Graphic Priming Experiment

\begin{tabular}{|c|c|c|c|c|c|c|}
\hline \multirow[b]{2}{*}{ Prime type and effects } & \multicolumn{2}{|c|}{$57 \mathrm{~ms}$} & \multicolumn{2}{|c|}{$86 \mathrm{~ms}$} & \multicolumn{2}{|c|}{$143 \mathrm{~ms}$} \\
\hline & $\begin{array}{l}\text { Naming } \\
\text { latencies }\end{array}$ & $\begin{array}{l}\text { Error } \\
\text { rates }\end{array}$ & $\begin{array}{l}\text { Naming } \\
\text { latencies }\end{array}$ & $\begin{array}{l}\text { Error } \\
\text { rates }\end{array}$ & $\begin{array}{l}\text { Naming } \\
\text { latencies }\end{array}$ & $\begin{array}{l}\text { Error } \\
\text { rates }\end{array}$ \\
\hline Graphically similar character & 568 & .045 & 497 & .046 & 521 & .037 \\
\hline Graphically similar pseudocharacter & 573 & .018 & 475 & .021 & 507 & .032 \\
\hline Unrelated character & 589 & .014 & 498 & .025 & 506 & .044 \\
\hline \multicolumn{7}{|l|}{ Net priming effects (Latency) } \\
\hline Character & $21 *$ & $-.031 *$ & 1 & $-.021 *$ & -15 & .007 \\
\hline Pseudocharacter & $16^{*}$ & -.004 & $23^{*}$ & .004 & -1 & .012 \\
\hline
\end{tabular}

$* p<.05$.

licates the findings of Perfetti and Tan (1998) with new materials and with what might have been a less sensitive procedure of repeated testing of targets. Thus, the results add support for the assumption that character identification is the result of input from radical units and for the assumption that inhibition results from activation of other characters sharing the radical unit only at the threshold stage of character identification. Radical-based inputs provide facilitation. If they activate more than one character to threshold level, inhibition emerges at the phonological level. When radicals are presented in pseudocharacter primes, there is no character unit to link to phonology, and so there is no inhibition.

\section{Event Related Potential (ERP) Evidence for Othographic and Phonological Effects}

Additional evidence consistent with early radical-based orthographic effects and later character-level phonological effects comes from a recent ERP study. Y. Liu, Perfetti, and Hart (2003) measured ERPs while Chinese speakers made judgments of meaning similarity and pronunciation for pairs of characters presented one at a time (this was essentially the same procedure used by Perfetti \& Zhang, 1995). They found that a positive ERP shift was observed at $200 \mathrm{~ms}$ after the onset of a character, which they interpreted as a graphic-processing component. This component was reduced when the character shared a radical (but not pronunciation) with a preceding character, reflecting the prior activation of the radical by the first character. Moreover, they found a clear ERP indicator of phonological interference between $400 \mathrm{~ms}$ and $500 \mathrm{~ms}$ after the onset of the second character when it was preceded by a homophone with which it did not share a radical. This result replicates with ERP the phonological interference results of Perfetti and Zhang (1995) and Zhang et al. (1999).

\section{General Discussion}

The significance of the current version of the model is not so much in its specific implementation as in the instantiation of the principles that are central to the lexical constituency model. The basic assumption is that identifying words involves word identity. This identity is specified as a triple of three word constituents, all of which are activated in normal reading processes. This multiple activation includes the rapid activation of phonology through direct connections between orthographic word forms and phonological word forms. When a character maps to a spoken word syllable, the spoken syllable is automatically activated. The model simulates only naming and its generality cannot be assumed, although we believe its general principles would apply well to other tasks. Certainly, when readers know they must produce a character "name," then character names must be activated. It is plausible that in semantic tasks, despite the evidence that phonology is activated, the strength or timing of phonology relative to semantics is different.

Most of the models developed for alphabetic reading have been exclusively about naming. In that context, the specific contribution of the implemented lexical constituency model is to demonstrate how a model of Chinese might accommodate existing modeling devices (e.g., representation of form and meaning levels, activation spread across levels) to the specific features of Chinese writing.

From this point of view, the major accommodation to be made is at the orthographic unit level, not at the level of connections between orthographic units and phonological units. Models for an alphabetic writing system must represent units at the letter level (or subsymbolic equivalents) and connect them to units at the phonological level to explain the facts of alphabetic reading, including nonword reading. A model for Chinese, we conclude, must represent units at the radical level. The difference between writing systems thus becomes not whether there are connections to phonology but rather what the relevant units are. In Chinese, the phonological units are syllables, linked to characters, which themselves include perceptually functional components.

The fact that the characters are decomposable into radicals is important in our model, which instantiates a compositional principle that is clearly visible in Chinese. However, it is equally clear that the composition is not the same as for alphabetic systems, and it is important not to be misled by a superficial analogy - that is, radicals are to characters as letters are to words. The radicals are orthographic units that may have value as morphemes (unlike letters). Some of the radicals themselves can be characters, having both meaning and syllable-level pronunciation. What they specifically do not have is systematic correspondences to phonemes, and even their cues to syllable pronunciations are not systematic in the same way that letter-phoneme mappings are.

Character radicals have properties that matter for character identification. As in the present model, radicals have a strong input role in a model of Chinese reading described by Taft and Zhu (1997). Their importance also has been demonstrated in experiments in the literature published in Chinese (Peng \& Tan, 1987). 
An important aspect of radical input orthography is radical position. Ding et al. (2004) found that whereas priming was facilitative when primes and targets shared radicals in the same position, priming did not occur when their shared radical was in a different position. Our model captures this position sensitivity by specifying the order and spatial relationship of radicals in the input level.

However, beyond their function as orthographic input into a character lexicon, the role of radicals is complex (e.g., in the meaning relations of semantic radicals; Feldman \& Siok, 1999). A particularly important complexity for naming is the validity of the phonetic radical - whether a character in which the phonetic radical appears has the same pronunciation as the radical does as a stand-alone character (i.e., a valid phonetic); or whether the character has a pronunciation different from the radical's pronunciation as a stand-alone character (i.e., an invalid phonetic). The implemented model presented here ignores the validity of the radicals (those that could be considered phonetic radicals). However, results of naming experiments suggest that characters with valid phonetics are named faster than are characters without valid phonetics (Fang et al., 1986; Hue, 1992; Seidenberg, 1985; Yang \& Peng, 1997) at least for low-frequency characters. Such a result has created a parallel with the Frequency $\times$ Regularity interaction in English (Paap \& Noel, 1991; Seidenberg, Waters, Barnes, \& Tannenhaus, 1984). ${ }^{9}$ The lexical constituency model can be extended to capture such effects by representing the pronunciations of radicals that are part of the orthographic character level and connecting their output to phonological units. The general structure of the model is compatible with allowing a stronger role for radicals, both semantic and phonetic, than is seen in the current version.

\section{The Pervasiveness of Phonology in Reading}

To consider again the more general questions of word identification, the evidence points to phonological processing in semantic tasks as well as in naming for both Chinese (e.g., Chua, 1999; Y. Liu et al., 2003; Perfetti \& Zhang, 1995; Xu et al., 1999) and English (Van Orden, 1987), whether or not its effects might be modulated by other variables (Jared \& Seidenberg, 1991). The present computational model could be modified to handle semantic processing and to simulate phonological interference effects. It has direct links between orthographic units and semantic units, allowing the possibility for a rapid retrieval of meaning without phonological involvement. However, parallel activation of phonological units from these orthographic units would also occur. Connections between these phonological units and semantic units lead to a second "route" to meaning via phonology. In the case of phonological units shared by two characters (homophones), some interference could result. It seems obvious that a model with direct connections from orthographic representations to meaning representations favors the direct, unmediated access to meaning. But the relative indeterminacy of form-meaning connections compared with form-form connections makes phonological involvement more likely for semantic decisions about single characters or pairs of characters.

The use of phonology in silent Chinese reading is surprising if one assumes that the structure of alphabetic writing systems is what is responsible for the phonological processes in reading. However, the discovery that phonology has a role in processing word meaning in Chinese (e.g., Chua, 1999; Perfetti \& Zhang, 1995; Xu et al., 1999) suggests that such an assumption is wrong. It is not the details of a writing system that ensure the use of phonology, but it is the more general design or adaptation of writing systems to human language. The varied adaptations of writing systems to language all accommodate the reader's (presumably natural) preference to use the writing system as a link to language, rather than as a new semiotic system in which graphs would forge new links to meanings. This makes phonology highly general or universal across writing systems, as has been argued by Perfetti et al. (1992).

\section{How the Writing System Makes a Difference}

Although reading universally makes use of phonology, the details of its use must depend on the writing system. We think there is enough evidence, some of which is based on analyses of writing systems and some is based on studies of reading, to suggest some differences in how phonology is used in Chinese compared with how it is used in English. Table 3 is a summary of some of the comparisons we take to be interesting.

\section{Orthography-to-Phonology Processes}

The first difference rests on the experimental evidence from Perfetti and Tan (1998) as simulated in the model described in this article. A key fact is the emergence of visual form-based graphic inhibition and the simultaneous emergence of phonological facilitation. Thus, a biphasic time course links an orthographic form effect to a phonological effect. No similar pattern has been reported for English, where effects of orthography and phonology have been observed to rise together (e.g., Perfetti \& Bell, 1991). Table 3 summarizes this difference in terms of cascade-style and threshold-style activation of phonology. The idea is that in an alphabetic system, the word-level units do not wait for a complete specification of all letter units prior to activating word level phonology (i.e., cascade style). In Chinese, the word-level phonology is not activated prior to a full orthographic specification of the character-hence, threshold style. (This distinction between cascade and threshold procedures was made by Coltheart et al., 1993.) As described, the model simulates this aspect of Chinese by threshold setting so that both graphic interference and phonological facilitation occur as a character reaches its threshold.

\section{Sublexical Units}

A difference in sublexical units is inherent in the writing system comparison. In an alphabetic system, letters and words represent two distinct levels, such that letters become constituent parts (wholly contained within) of the whole word. In Chinese, the component graphic forms (radicals) themselves are often standalone characters. Thus they participate in both the higher word

\footnotetext{
${ }^{9}$ Whether phonology is functional for words of high as well as low frequency is an important point beyond our purpose. In tasks other than naming, phonological effects have been observed for high frequency words in English (Berent \& Perfetti, 1995; Perfetti \& Bell, 1991) and in Chinese (Zhang et al., 1999). Even in English naming, high frequency words are affected by phonological consistency of spellings (Jared, 1997).
} 
Table 3

A Comparison of Phonological Aspects of Alphabetic and Nonalphabetic Word Reading

\begin{tabular}{ll}
\hline \multicolumn{1}{c}{ Alphabetic (English) } & \multicolumn{1}{c}{ Logographic (Chinese) } \\
\hline $\begin{array}{c}\text { Phonology activated with } \\
\text { orthography - cascade style }\end{array}$ & $\begin{array}{c}\text { Phonology activated with } \\
\text { orthography - threshold style } \\
\text { Sublexical units: proper parts }\end{array}$ \\
$\begin{array}{l}\text { Shonological units: wholes are parts } \\
\text { Phonology can "mediate" meaning } \\
\text { Phonological coherence more apt }\end{array}$ & $\begin{array}{l}\text { Mediation is a dubious concept } \\
\text { Phonological diffusion more apt }\end{array}$ \\
\hline
\end{tabular}

level and the "sublexical" level. They participate in different ways at these two levels, that is, as a word at the higher level and as a potential cue to meaning or pronunciation at the sublexical level. The question is whether these dual lexical and sublexical roles matter for processing. Indeed, this duality could be the main difference responsible for the cascade versus threshold difference described above. The threshold feature of Chinese identification may derive from the fact that a component of a character (e.g., a semantic radical) activates all characters that contain it in addition to activating its own character representation. The inhibition of highly activated competitors then follows as a means for the identification system to secure a lexical identity (including its phonology).

\section{Prelexical Phonology}

This difference follows from the basic differences in sublexical units. Thus prelexical phonology can occur in an alphabetic system because the system contains sublexical units (phonemes) that can activate immediately, prior to the activation of the word. The phonology that is activated in a Chinese character may also include the phonology of those component radicals within the character that are themselves characters, as well as the character as a whole. But because such a component radical is not prelexical, its phonology, whether activated before that of the character as a whole or not, cannot be prelexical in the same sense as it can be in an alphabetic system.

\section{Phonological Mediation}

Because a Chinese character typically has so many homophones, the pronunciation of the character by itself is not adequately constraining. It will not pick out a unique morpheme. This means that the use of the phonology to access the meaning-the usual sense of phonological mediation-would be a maladaptive process. Indeed, it would be an indeterminate process. Phonological "diffusion" captures the idea that a given level of phonological activation is distributed across many lexical units. Indeed, there are results to suggest that the degree of diffusion (as indexed by the number of homophones a character has) influences phonological mediation (Tan \& Perfetti, 1997). Although one might want to argue that this is a basic difference in the two systems-thus allowing mediation in this sense for alphabetic reading-the difference is one of degree, although a very large one. We think there is a lesson to apply from this analysis of Chinese to alphabetic systems. In both systems, one can think of phonology, not as an instrument to meaning, but rather as a constituent of a word that constrains the identification process. The triple constituents of graphic form, phonological form, and meaning uniquely constrain the identification of a word. We return to this point in the final discussion below.

\section{Implications for Theories of Reading: Routes, Names, Identities, and Mediation}

By highlighting differences as well as similarities, we can see some broader issues of comparison at meta-theoretical levels that are significant for models of reading. Models developed for English word reading have focused on naming printed words and the question of whether theories need one route or two for naming. For Chinese, this question takes on a different quality. Chinese word reading, like alphabetic reading, produces a phonological output from a graphic input. Chinese, again like alphabetic reading, involves a semantic level of representation. In the dual-route cascaded model (Coltheart et al., 2001), the orthographic--lexical route is actually two routes, one from the orthographic lexicon (spelling-specified word representations) directly to a phonological output lexicon and one that goes from the orthographic lexicon to semantics and then to the phonological lexicon. The phonological route is nonlexical, from letter strings through letter-phoneme conversion to the phonological output lexicon (with the possibility of a late influence from semantics through the phonological output lexicon). Thus, the dual-route cascaded model actually has three routes-lexical-semantic, lexical-nonsemantic, and nonlexicalphonological (grapheme-phoneme).

As is clear from Figure 2, our model of Chinese includes the first two routes as possibilities. It is the third nonlexical route that has to be different for Chinese. To be clear, a kind of nonlexical phonology is possible in Chinese, because of the phonetic radicals that are part of many compound characters. When a phonetic radical has the same pronunciation as the character as a whole, character naming may be faster, implicating a process that is sensitive to the pronunciation of radicals within characters (Fang et al., 1986; Seidenberg, 1985). However, because the phonetic radical is usually also a stand-alone character, it has its own representation in the orthographic lexicon. This duality of representation - a radical is both a part and a whole-is quite different from alphabetic systems, in which letters and words occupy unique and nonoverlapping levels of representation. Beyond this systemdependent difference in the representation system, there is a related unique constraint on Chinese at the character level. Even with a phonetic radical, the character itself ultimately determines its name. The successful retrieval of a character's name is determined by the character's learned connection to a syllable/word in the spoken language. This is quite different from the determinism that a fully regular letter string exerts on the naming of a word in an alphabetic system.

However, before we conclude that Chinese and English differ on the number of routes they have for naming, we might reconsider the concept of naming itself. Naming is not a very useful way to refer to word reading. Presumably for reasons of experimental convenience, the research field has referred to a process of "naming" words (hence, "naming" experiments). But written words, unlike people and places, do not have names so much as pronunciations. This is a property they share with spoken words. Note that both written words and spoken words are "mispronounced," not 
"misnamed." A word has an identity, not a name, and word identification is the expression of that identity through pronunciation. This is as true for a Chinese character as for an English or Spanish word.

At a general level, the lexical constituency model promotes this way of thinking about word identity. Rather than having a name, a printed form is one constituent, the orthographic constituent of a word identity. Its other two constituents, the phonological and the semantic, complete the word's identity. What this means for the alphabetic-nonalphabetic comparison is that a Chinese character is pronounced by retrieving the syllable word that is part of the word's identity, given a character input. The pronunciation of printed English words is similar at a high enough level. One pronounces a word by retrieving its identity and producing its phonological constituent. The difference is just that along the way to looking up a word identity, English allows prelexical processes that use sublexical units to assist (consistent spellings) and hinder (inconsistent spellings) the final outcome. The focus on this aspect of alphabetic reading is quite justified by the nature of alphabetic writing. But in Chinese, the sublexical units that might assist character reading do not operate in quite the same way because they participate in multiple levels of representation in different ways.

Finally, we return briefly to an issue we raised in the introduction, the question of phonological mediation - the idea that meanings are accessed in reading by first retrieving the spoken language - and the assumption that mediation in Chinese would be very inefficient because of homophones. As we have observed, dozens of characters share a pronunciation, implying that phonological activation would have little purpose. Nevertheless, the evidence strongly suggests that phonological interference occurs in a simple semantic categorization task (e.g., Chua, 1999; Xu et al., 1999) as well as in character meaning similarity decisions (Perfetti \& Zhang, 1995; Y. Liu et al., 2003; Zhang et al., 1999). A functionalist perspective encourages a search for some value for the phonology that gets activated, and, in English, mediation to meaning has provided this function. For Chinese, however, such a mediation function seems less likely. Whereas Chinese research has been directed at detecting phonology, little has been directed at assessing its possible mediating function (cf. Tan \& Perfetti, 1997).

At first glance, this dissociation of process from function presents a question for a universal perspective on reading. Is phonology only functional in alphabetic and syllabary systems but not in Chinese? There are several possible resolutions to this question. One is that the learned associations between printed word forms and spoken word forms are too powerful to inhibit, and they force process without observable function. Thus, Chinese would have a nonfunctional phonology in silent reading for meaning. A second possibility is that spoken word forms support down-stream (postlexical access) processes and that their automatic activation as a constituent of word identification serves these memory and comprehension processes, irrespective of any mediation (as argued nearly 20 years ago by Perfetti \& McCutchen, 1982). A third solution is based on the sense of phonological mediation proposed by Van Orden and Goldinger (1994): Phonological mediation is related to the "negotiated" sense of mediation (cf. "labor mediation") rather than in its usual sense of indirectly instrumental. In alphabetic systems, phonology stabilizes word identity, even if it does not cause access to word meaning. This role of phonology holds also in Chinese. A character connected to a pronunciation is more definitive (reducing error in identification) than one that is not connected, even if other characters share that pronunciation. We think all three of these observations are useful in understanding why phonology might be used even in a system where, at first glance, it seems to be unhelpful. More generally, conceptualizing word reading as an identification achieved through the convergence of a word's three constituents leads to a functional concept of phonological mediation that can replace the instrumental sense in all writing systems.

There are many elements of Chinese word reading beyond what we have discussed here and certainly more than are addressed in the implemented version of the lexical constituency model. We suggest that the analysis of word identification underlying the model is useful both for extensions of the model to other aspects of Chinese reading and for conceptualizing the word identification process in alphabetic writing systems. More generally, the comparative analysis of reading across writing systems is important for seeing the larger picture of how reading works.

\section{References}

Baluch, B., \& Besner, D. (1991). Visual word recognition: Evidence for strategic control of lexical and nonlexical routines in oral reading. Journal of Experimental Psychology: Learning, Memory, and Cognition, 17, 644-652.

Baron, J., \& Strawson, C. (1976). Use of orthographic and word-specific knowledge in reading words aloud. Journal of Experimental Psychology: Human Perception and Performance, 2, 386-393.

Berent, I., \& Perfetti, C. A. (1995). A rose is a REEZ: The two-cycles model of phonology assembly in reading English. Psychological Review, 102, 146-184.

Besner, D. (1990). Does the reading system need a lexicon? In W. MarslenWilson (Ed.), Lexical representation and process (pp. 291-316). Cambridge, MA: MIT Press.

Besner, D., \& Smith, M. C. (1992). Basic processes in reading: Is the orthographic depth hypothesis sinking? In R. Frost \& L. Katz (Eds.), Orthography, phonology, morphology, and meaning (pp. 45-66). Amsterdam: North-Holland.

Chua, F. (1999). Phonological recoding in Chinese logograph recognition. Journal of Experimental Psychology: Learning, Memory, and Cognition, 25, 876-891.

Chen, H.-C., \& Shu, H. (2001). Lexical activation during recognition of Chinese characters: Evidence against early phonological activation. Psychonomic Bulletin \& Review, 8, 511-518.

Chen, M. J., Yung, Y. F., \& Ng, T. W. (1988). The effect of context on the perception of Chinese characters. In I. M. Liu, H.-C. Chen, \& M. J. Chen (Eds.), Cognitive aspects of the Chinese language (pp. 27-39). Hong Kong, China: Asian Research Service.

Cheng, C. M., \& Shih, S. I. (1988). The nature of lexical access in Chinese: Evidence from experiments on visual and phonological priming in lexical judgment. In I. M. Liu, H.-C. Chen, \& M. J. Chen (Eds.), Cognitive aspects of the Chinese language (pp. 1-14). Hong Kong, China: Asian Research Service.

Coltheart, M. (1978). Lexical access in simple reading tasks. In G. Underwood (Ed.), Strategies of information processing (pp. 151-216). New York: Academic Press.

Coltheart, M., Curtis, B., Atkins, P., \& Haller, M. (1993). Models of reading aloud: Dual-route and parallel-distributed-processing approaches. Psychological Review, 100, 589-608.

Coltheart, M., Rastle, K., Perry, C., Langdon, R., \& Ziegler, J. (2001). The 
DRC model: A model of visual word recognition and reading aloud. Psychological Review, 108, 204-258.

DeFrancis, J. (1989). Visible speech: The diverse oneness of writing systems. Honolulu: University of Hawaii.

Ding, G., Peng, D.-L., \& Taft, M. (2004). The nature of the mental representation of radicals in Chinese: A priming study. Journal of Experimental Psychology: Learning, Memory, and Cognition, 30, 530539.

Fan, K. Y. (1986, May). Graphic symbols of Chinese characters. Paper presented at the symposium on Chinese character modernization, Beijing, China.

Fang, S. P., Horng, R. Y., \& Tzeng, O. J. L. (1986). Consistency effects in the Chinese character and pseudo-character naming tasks. In H. S. R. Kao \& R. Hoosain (Eds.), Linguistics, psychology, and the Chinese language (pp. 11-21). Hong Kong, China: Center of Asian Studies.

Feldman, L. B., \& Siok, W. T. (1999). Semantic radicals in phonetic compounds: Implications for visual character recognition in Chinese. In J. Wang, A. Inhoff, \& H.-S. Chen (Eds.), Reading Chinese script: A cognitive analysis (pp. 19-35). Mahwah, NJ: Erlbaum.

Frost, R. (1994). Prelexical and postlexical strategies in reading: Evidence from a deep and a shallow orthography. Journal of Experimental Psychology: Learning, Memory, and Cognition, 20, 116-129.

Frost, R. (1995). Phonological computation and missing vowels: Mapping lexical involvement in reading. Journal of Experimental Psychology: Learning, Memory, and Cognition, 21, 398-408.

Frost, R., Katz, L., \& Bentin, S. (1987). Strategies for visual word recognition and orthographical depth: A multilingual comparison. Journal of Experimental Psychology: Human Perception and Performance, 13, $104-115$.

Grainger, J., \& Jacobs, A. M. (1994). A dual read-out model of word context effects in letter perception: Further investigations of the word superiority effect. Journal of Experimental Psychology: Human Perception and Performance, 20, 1158-1176.

Grainger, J., \& Jacobs, A. M. (1996). Orthographic processing in visual word recognition: A multiple read-out model. Psychological Review, 203, 518-565.

Harm, M. W., \& Seidenberg, M. S. (1999). Phonology, reading acquisition, and dyslexia: Insights from connectionist models. Psychological Review, 106, 491-528.

Hoosain, R., \& Osgood, C. E. (1983). Information processing times for English and Chinese words. Perception and Psychophysics, 34, 573577.

Hue, C. W. (1992). Recognition processes in character naming. In H.-C. Chen \& O. J. L. Tzeng (Eds.), Language processing in Chinese (pp. 93-107). Amsterdam: North-Holland.

Hung, D. L., Tzeng, O. J. L., \& Tzeng, A. K. Y. (1992). Automatic activation of linguistic information in Chinese character recognition. In R. Frost \& L. Katz (Eds.), Orthography, phonology, morphology, and meaning (pp. 119-130). Amsterdam: North-Holland.

Jacobs, A. M., Rey, A., Ziegler, J. C., \& Grainger, J. (1998). MROM-p: An interactive activation, multiple readout model of orthographic and phonological processes in visual word recognition. In J. Grainger \& A. M. Jacobs (Eds.), Localist connectionist approaches to human cognition (pp. 147-188). Mahwah, NJ: Erlbaum.

Jared, D. (1997). Spelling-sound consistency affects the naming of highfrequency words. Journal of Memory and Language, 36, 505-529.

Jared, D., \& Seidenberg, M. S. (1991). Does word identification proceed from spelling to sound to meaning? Journal of Experimental Psychology: General, 120, 358-394.

Jin, J. H. (1985). On the Chinese character. Chinese Character Reformation, $5,13-15$.

Lam, A., Perfetti, C. A., \& Bell, L. (1991). Automatic phonetic transfer in bidialectal reading. Applied Psycholinguistics, 12, 299-311.

Language and Teaching Institute of Beijing Linguistic College. (1986).
Xiandai Hanyu Pinlu Cidian [Modern Chinese frequency dictionary]. Beijing, China: Beijing Language Institute Press.

Leong, C. K. (1973). Reading in Chinese with reference to reading practices in Hong Kong. In J. Downing (Ed.), Comparative reading: Crossnational studies of behavior and processes in reading and writing (pp. 383-402). New York: Macmillan.

Leong, C. K. (1997). Paradigmatic analysis of Chinese word reading: Research findings and classroom practices. In C. K. Leong \& R. M. Joshi (Eds.), Cross-language studies of learning to reading and spell: Phonological and orthographic processing (pp. 379-417). Kluwer Academic.

Li, P., \& Yip, C. W. (1996). Lexical ambiguity and context effects in spoken word recognition: Evidence from Chinese. In G. Cottrell (Ed.), Proceedings of the 18th Annual Conference of the Cognitive Science Society (pp. 228-232). Mahwah, NJ: Erlbaum.

Liu, I.-M. (1995). Script factors that affect literacy: Alphabetic vs. logographic languages. In I. Taylor \& D. R. Olson (Eds.), Scripts and literacy (pp. 145-162). Amsterdam: Kluwer Academic.

Liu, Y., Perfetti, C. A., \& Hart, L. (2003). ERP evidence for the time course of graphic, phonological, and semantic information in Chinese meaning and pronunciation decisions. Journal of Experimental Psychology: Learning, Memory, and Cognition, 29, 1231-1247.

Mattingly, I. G. (1987). Morphological structure and segmental awareness. Cahiers de Psychologie Cognitive, 7, 488-493.

Mattingly, I. G. (1992). Linguistic awareness and orthographic form. In R. Frost \& L. Katz (Eds.), Orthography, phonology, morphology, and meaning (pp. 11-26). Amsterdam: Elsevier Science.

Paap, K. R., \& Noel, R. W. (1991). Dual-route models of print and sound: Still a good horse race. Psychological Research, 53, 13-24.

Peng, D.-L. \& Tan, L. H. (1987). Ci pin he yu jing zai zhong wen shuang zi ci shi bie zhong de zuo yong [Effects of word frequency and semantic context on Chinese two-character recognition]. Journal of Psychology, $4,18-25$.

Perfetti, C. A., \& Bell, L. (1991). Phonemic activation during the first 40 ms of word identification: Evidence from backward masking and masked priming. Journal of Memory and Language, 30, 473-485.

Perfetti, C. A., Bell, L., \& Delaney, S. (1988). Automatic phonetic activation in silent word reading: Evidence from backward masking. Journal of Memory and Language, 27, 59-70.

Perfetti, C. A., \& Hart, L. (2001). The lexical basis of comprehension skill. In D. Gorfein (Ed.), The consequences of meaning selection (pp. 67-86). Washington, DC: American Psychological Association.

Perfetti, C. A., \& McCutchen, D. (1982). Speech processes in reading. In N. Lass (Ed.), Speech and language: Advances in basic research and practice (pp. 237-269). New York: Academic Press.

Perfetti, C. A., \& Tan, L. H. (1998). The time-course of graphic, phonological, and semantic activation in Chinese character identification. Journal of Experimental Psychology: Learning, Memory, and Cognition, 24, 1-18.

Perfetti, C. A., \& Tan, L. H. (1999). The constituency model of Chinese word identification. In J. Wang, A. Inhoff, \& H.-S. Chen (Eds.), Reading Chinese script: A cognitive analysis (pp. 115-134). Mahwah, NJ: Erlbaum.

Perfetti, C. A., \& Zhang, S. (1991). Phonological processes in reading Chinese characters. Journal of Experimental Psychology: Learning, Memory, and Cognition, 17, 633-643.

Perfetti, C. A., \& Zhang, S. (1995). Very early phonological activation in Chinese reading. Journal of Experimental Psychology: Learning, Memory, and Cognition, 21, 24-33.

Perfetti, C. A., Zhang, S., \& Berent, I. (1992). Reading in English and Chinese: Evidence for a "universal" phonological principle. In R. Frost \& L. Katz (Eds.), Orthography, phonology, morphology, and meaning (pp. 227-248). Amsterdam: North-Holland.

Plaut, D. C., \& Booth, J. R. (2000). Individual and developmental differ- 
ences in semantic priming: Empirical and computational support for a single-mechanism account of lexical processing. Psychological Review, 107, 786-823.

Plaut, D. C., McClelland, J. L., Seidenberg, M. S., \& Patterson, K. (1996). Understanding normal and impaired word reading: Computational principles in quasi-regular domains. Psychological Review, 103, 56-115.

Pollatsek, A., Tan, L. H., \& Rayner, K. (2000). The role of phonological codes in integrating information across saccadic eye movements in Chinese character identification. Journal of Experimental Psychology: Human Perception and Performance, 26, 607-633.

Shen, D., \& Forster, K. I. (1999). Masked phonological priming in reading Chinese words depends on the task. Language and Cognitive Processes, 14, 429-459.

Seidenberg, M. S. (1985). The time course of phonological code activation in two writing systems. Cognition, 19, 1-30.

Seidenberg, M. S., \& McClelland, J. L. (1989). A distributed, developmental model of word recognition and naming. Psychological Review, 96, 523-568.

Seidenberg, M. S., \& McClelland, J. L. (1990). More words but still no lexicon: Reply to Besner et al. (1990). Psychological Review, 97, 447452

Seidenberg, M. S., Waters, G. S., Barnes, M. A., \& Tanenhaus, M. K. (1984). When does irregular spelling or pronunciation influence word recognition? Journal of Verbal Learning and Verbal Behavior, 23, 383-404.

Spinks, J. A., Liu, Y., Perfetti, C. A., \& Tan, L. H. (2000). Reading Chinese characters for meaning: The role of phonological information. Cognition, 76, B1-B11.

Taft, M., \& Zhu, X. (1997). Submorphemic processing in reading Chinese. Journal of Experimental Psychology: Learning, Memory, and Cognition, 23, 761-775.

Tan, L. H., Hoosain, R., \& Peng, D.-L. (1995). Role of early presemantic phonological code in Chinese character identification. Journal of Experimental Psychology: Learning, Memory, and Cognition, 21, 43-54.

Tan, L. H., \& Perfetti, C. A. (1997). Visual Chinese character recognition: Does phonological information mediate access to meaning? Journal of Memory and Language, 37, 41-57.

Tan, L. H., \& Perfetti, C. A. (1998). Phonological codes as early sources of constraint in Chinese word identification: A review of current discoveries and theoretical accounts. Reading and Writing: An Interdisciplinary Journal, 10, 165-200.

Tan, L. H., \& Perfetti, C. A. (1999). Phonological activation in visual identification of Chinese two-character words. Journal of Experimental Psychology: Learning, Memory, and Cognition, 25, 382-393.

Tzeng, O. J. L., \& Hung, D. L. (1978). Reading the Chinese character: Some basic research. Acta Psychologica Taiwanica, 20, 45-49.

Tzeng, O. J. L., Hung, D. L., \& Wang, W. S.-Y (1977). Speech recoding in reading Chinese characters. Journal of Experimental Psychology: Human Memory and Learning, 3, 621-630.
Van Orden, G. C. (1987). A ROWS is a ROSE: Spelling, sound, and reading. Memory \& Cognition, 15, 181-198.

Van Orden, G. C., \& Goldinger, S. D. (1994). The interdependence of form and function in cognitive systems explains perception of printed words. Journal of Experimental Psychology: Human Perception and Performance, 20, 1269-1291.

Van Orden, G. C., Pennington, B., \& Stone, G. (1990). Word identification in reading and the promise of subsymbolic psycholinguistics. Psychological Review, 97, 488-522.

Wang, W. S.-Y. (1973, February). The Chinese language. Scientific American, 228, 50-60.

Weekes, B. S., Chen, M. J. \& Yu, B.-L. (1998). Differential effects of phonological priming on Chinese word recognition. Reading and Writing: An Interdisciplinary Journal, 10, 47-68.

Xu, Y., Pollatsek, A., \& Potter, M. (1999). The activation of phonology during silent Chinese word reading. Journal of Experimental Psychology: Learning, Memory, and Cognition, 25, 838-857.

Yang, H., \& Peng, D.-L. (1997). The learning and naming of Chinese characters of elementary school children. In H.-C. Chen (Ed.), Cognitive processing of Chinese and related Asian languages (pp. 323-346). Hong Kong, China: The Chinese University Press.

Yoon, H.-K., Bolger, D. J., Kwon, O.-S., \& Perfetti, C. A. (2002). Subsyllabic units in reading: A difference between Korean and English. In L. Vehoeven, C. Elbrow, \& P. Reitsma (Eds.), Precursors of functional literacy (pp. 139-163). Amsterdam and Philadelphia: John Benjamins.

Zhang, S., \& Perfetti, C. A. (1993). The tongue twister effect in reading Chinese. Journal of Experimental Psychology: Learning, Memory, and Cognition, 19, 1082-1093.

Zhang, S., Perfetti, C. A., \& Yang, H. (1999). Whole-word, frequencygeneral phonology in semantic processing of Chinese characters. Journal of Experimental Psychology: Learning, Memory, and Cognition, 25, $858-875$.

Zhou, X., \& Marslen-Wilson, W. (1996). Direct visual access is the only way to access the Chinese mental lexicon. In G. Cottrell (Ed.), Proceedings of the 18th Annual Conference of the Cognitive Science Society (pp. 714-719). Hillsdale, NJ: Erlbaum.

Zhou, Y. (1978). Xian dai han zi sheng pang de biao yin gong neng wen ti [To what degree are the "phonetics" of present-day Chinese characters still phonetic?]. Zhongguo Yuwen, 146, 172-177.

Zhu, X. (1988). Analysis of cueing function of phonetic components in modern Chinese. In X. Yuan (Ed.), Proceedings of the symposium on the Chinese language and characters (pp. 85-99). Beijing, China: Guang Ming Daily Press.

Received October 11, 2000

Revision received May 4, 2004

Accepted May 17, 2004 